\title{
THERMOCHROMIC PAINTING SYSTEMS - A NEW APPROACH TO INCREASE OCCUPATIONAL SAFETY
}

\author{
'Zuzana TATíČKOVÁ, ' Viktor KREIBICH, ' Jan KUDLÁČEK, ' Jakub SVOBODA \\ ${ }^{1}$ CTU in Prague - Czech Technical University in Prague, Prague, Czech Republic, EU, \\ Zuzana.Fickova@fs.cvut.cz, Viktor.Kreibich@fs.cvut.cz, Jan.Kudlacek@fs.cvut.cz, \\ Jakub.svoboda1@fs.cvut.cz
}

https://doi.org/10.37904/metal.2021.4187

\begin{abstract}
Improving safety in mechanical engineering is still a topical issue. This article focuses on the introduction of a new thermochromic coating system, its development, and testing. The thermochromic coating systems are special paints that have the ability to change color and prevent burns. These systems can be used in environments exposed to temperature as an element of active safety.

Research in the field of interactive coatings for safety purposes is carried out at the CTU in Prague as part of a national research project. In this project, a completely new coating system with thermochromic properties was designed. During the design phase, it was necessary to select a suitable primer inert to the thermochromic pigment. Due to the high sensitivity of the pigment, it was necessary to choose a suitable method of mixing. Several tests were performed to verify the application and functional properties of the thermochromic paints.

The pigment Apex TH50 from the company Capricorn Specialty Chemicals was chosen for the development of the interactive coating system. This pigment changes the hue of the color in the temperature range of $47-52{ }^{\circ} \mathrm{C}$. This temperature range was chosen due to the mechanism of burn. The tolerable contact temperature is around $44^{\circ} \mathrm{C}$. The maximum temperature at which changes on human skin are reversible is up to about $55^{\circ} \mathrm{C}$, but only with short-term contact. Therefore, if a worker notices a changing hue of the color in an exposed area, he will be visually alerted to unsafe contact or subsequent burn injury.
\end{abstract}

Keywords: Thermochromic, Pigment, Interactive, Heat-sensitive, Color, Surface Treatment, Safety

\section{INTRODUCTION}

Interactive paints are currently being developed in response to specific surface functionalization requirements. We can talk about special properties of paints that increase service life (self-healing coating material), prevent property damage (antigraffiti coating material), or serve as an indicator of temperature change (thermochromic coating material).

Thermochromism is according to J.H. Day [1] defined as "noticeable reversible color change brought about by the boiling point of each liquid, boiling point of a solvent in the case of a solution, or the melting point for solid". However, it is necessary to distinguish how the color change is implemented. In technical practice, so-called thermochromic liquid crystals and leuco-based pigments are currently used. Thermochromic liquid crystals as a mass at the liquid-crystal interface respond to a large number of stimuli (magnetic field, pressure, humidity, and chemicals), do not have a long life and are therefore not suitable for application in paints. [2,3]

When using thermochromism in paints, thermochromic pigments are most often used on a leuco basis, where the pigment has a certain shade at room temperature and discolors at increased temperature. There are irreversible pigments (temperature transition occurs only once), partially reversible (the number of temperature transitions is limited), and reversible pigments. [3,4] 
Reversible pigments are currently produced as leuco-based molecular charge transfer complexes. These are organic substances in the state of microcapsules. These substances consist of a component that supplies colors - color developers, a component that determines the transition temperature and shadow intensity, and a component that stabilizes the properties in the temperature range. [2,4], These components are mixed in the proportions given by the manufacturer and "sealed" in microcapsules. The core structure is thus separated from the capsule shell. $[2,3,4]$

During research at the Faculty of Mechanical Engineering CTU in Prague, we focused on the use of thermochromism to actively protect the health of workers in the industry. In this research, a completely new reversible thermochromic coating was designed and tested, which serves as an indicator of overheating, when the temperature changes, it quickly informs the operator of the possible risk of injury. Because the color change is visually unambiguous, there can be, for example, a wrong reading, as can be the case, for example, when reading values from a temperature sensor. $[10,11,12]$

Protecting workers' health from the risk of burns is still a topical issue in the industry. In the Czech Republic, in the industrial sector, an average of 795 occupational accidents are reported annually in the category of "burns, scalds, frostbite". [5]

\section{DESIGN OF THERMOCHROMIC PAINT}

The idea of creating a new paint with thermochromic properties was specified by participating in the Competence Center project. After examining the market, a pigment from Capricorn Special Chemicals was chosen. The thermochromic pigment is organic, in the form of microcapsules (Figure 1). Its size is up to $7 \mu \mathrm{m}$. The transition temperature can be selected according to the product line (TH30, TH40, TH50, TH60). The maximum allowable temperature to which the pigment can be exposed is $20{ }^{\circ} \mathrm{C}$ for 10 minutes. [6] In the experiment, it was necessary to create several formulations to verify the functionality of both the pigment and the overall coating system.
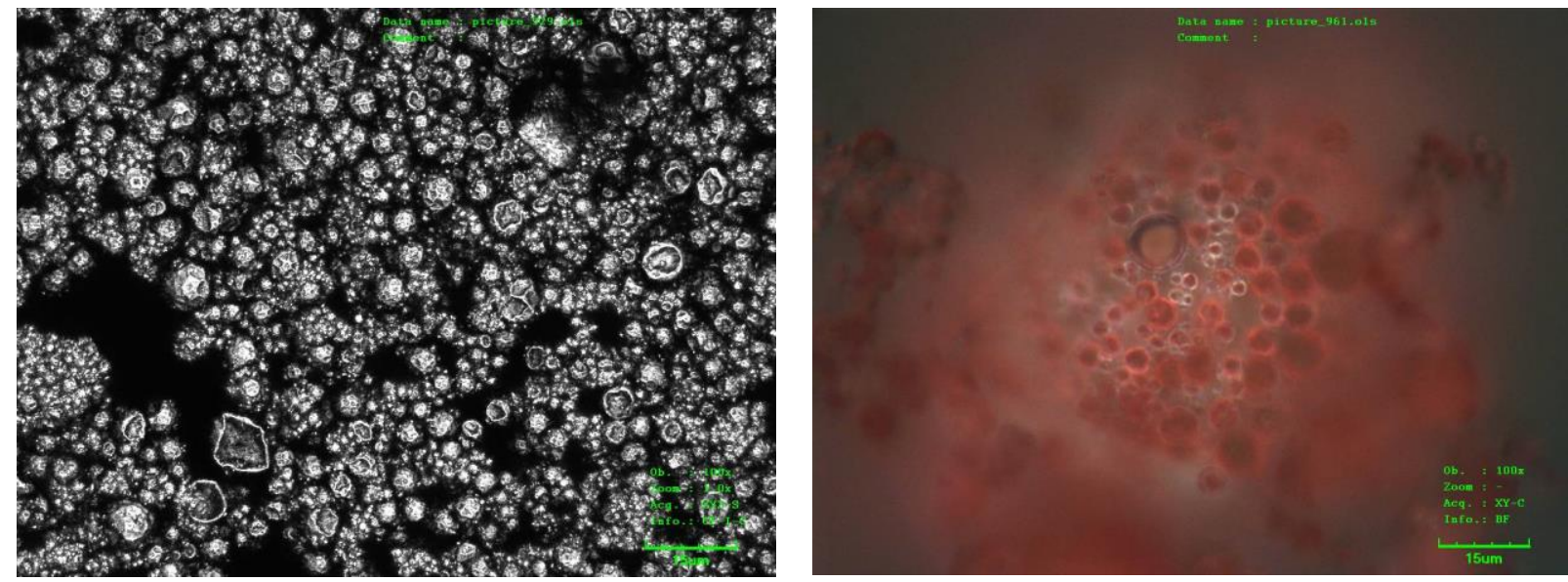

Figure 1 The appearance of APEX TH50 pigment. The shape of the pigment is spherical with a size of up to $7 \mu \mathrm{m}$. Scanned with an Olympus Lext OLS 3000 confocal microscope

The first test formulation was created in cooperation with VITON s.r.o. The aim was to verify the thermochromic properties of the pigment - according to the technical sheet, it should discolor after heating to the temperature. After cooling to ambient temperature, it should have taken to the original shade.

The formulation was created experimentally. A one-component acrylic polyol was chosen as the base coating material. The Apex $\mathrm{TH} 30$ pigment was dispersed in a standard manner, using a saw - tooth stirrer. The 
application was carried out on a glass sample, with a film applicator, so that the color change was more clearly visible (Figure 2).
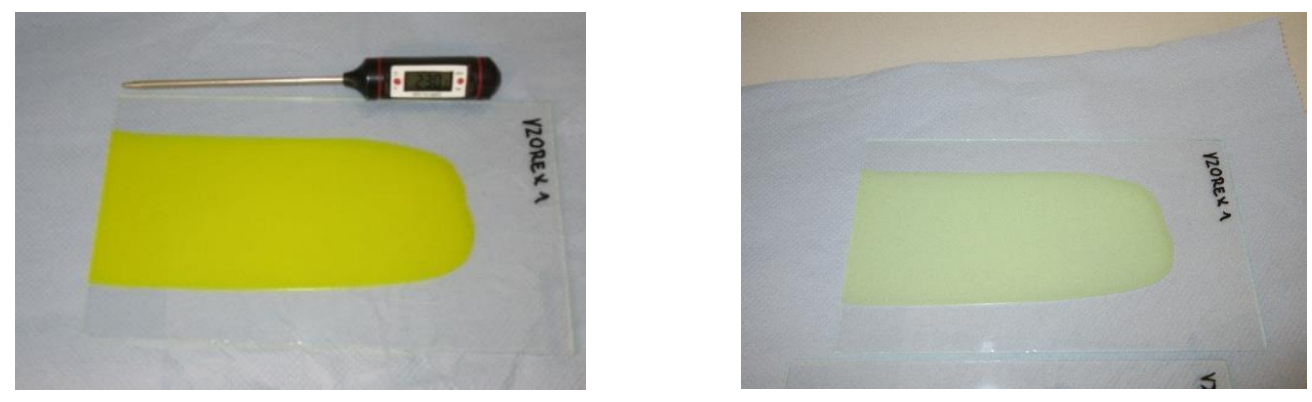

Figure 2 The first test, paint on the left at room temperature, right after heating

Furthermore, a larger amount of thermochromic paint with the same base as APEX TH30 (yellow, dark blue) and APEX TH60 (black) was formed. These coating systems were applied to samples of S235JR material to verify the behavior on a metal substrate and to determine the mechanical properties (Figure 3). [11]

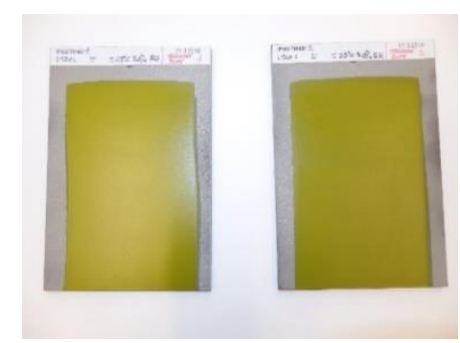

TH30

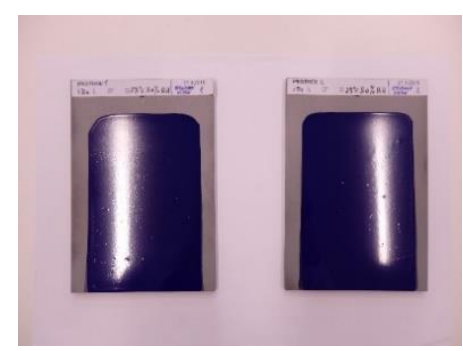

TH30

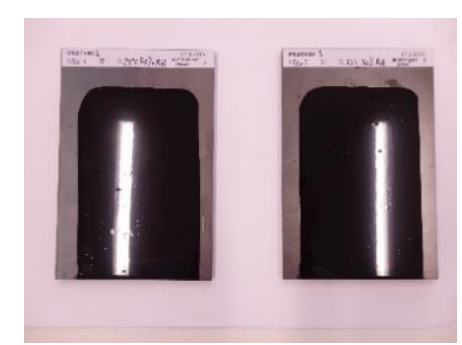

TH60

Figure 3 Samples of the IP01 coating system applied on a metal substrate

From the conclusions from the first test formulation and the focus on increasing safety, the pigment APEX TH50 with a temperature transition of $47-52^{\circ} \mathrm{C}$, red, was selected for further research. This temperature range is at the limit where early warning can protect the worker from burns (at temperatures above $44{ }^{\circ} \mathrm{C}$, skin damage occurs, but this is reversible up to approximately $55^{\circ} \mathrm{C}$. Above $60^{\circ} \mathrm{C}$, permanent burns already occur). [7]

The results from the first formulation were the motivation for testing the interaction of the pigment with different primers to form a highly functional coating. The interaction of the thermochromic pigment with the already pigmented base was also investigated and the effect of the dispersion on the properties of the resulting paint was investigated. Therefore, the following experimental scheme was proposed.

- Verification of the properties of the already formed formulation - acrylic polyol with yellow pigment and thermochromic pigment. Marked as IP02.

- New paint formulation with self-priming acrylic base, water-soluble, with yellow pigment and thermochromic pigment. Marked as IP03.

- New paint formulation with polyurethane base, with yellow pigment and thermochromic pigment. Marked as IP04.

The resulting coating formulation thus has an orange color at normal temperatures (around $20^{\circ} \mathrm{C}$ ), at increased temperatures the red thermochromic pigment discolors, and the coating remains yellow. The coloring with the base pigment was also designed because the thermochromic pigment itself does not sufficiently cover. 
Three types of test specimens were used for the experiment - Q panel (material S235JRG1), a sheet made of structural steel S235, and glass specimens. The Q panels were degreased with technical gasoline before application, the sheets were pre-treated with the technology of blasting with artificial corundum crumbs to grade Sa 3. The glass samples were degreased with technical gasoline before application.

Samples of the first series were applied with a film applicator, samples of the second series were created using an airless spraying (Figure 4, Figure 5). [12]

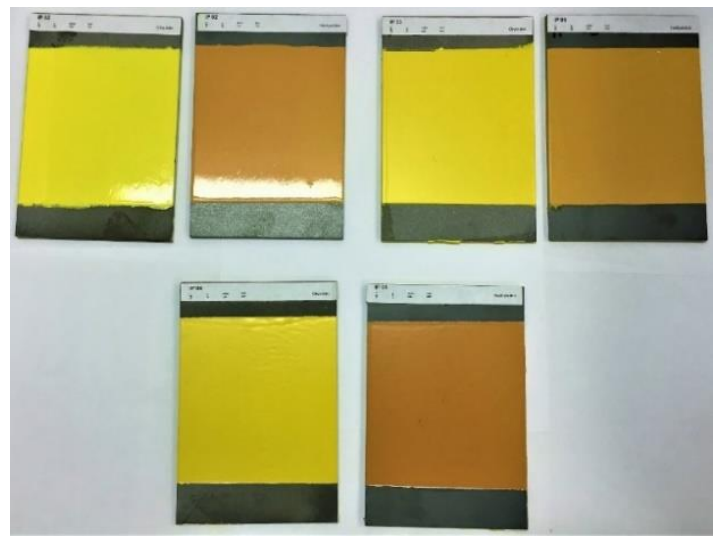

Figure 4 Results of the 1 st series before testing. Top left: IP02; IP03 and IP04. On the left, the sample is always heated to the color transition temperature

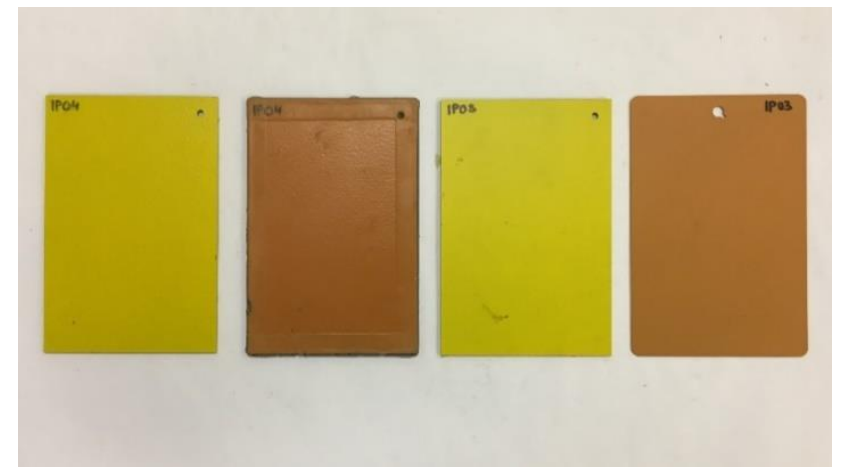

Figure 5 Results of the 2 nd series before testing. From left IP04 and IP03. On the left, the sample is always heated to the color transition temperature.

As part of the development of paints, two types of stirrers were used - a saw - tooth stirrer and a rotor-stator stirrer. The saw - tooth stirrer disperses by creating high shear stress and is also suitable for very small particles. [8,9], The rotor-stator stirrer works on the following principle: the rotor generates a high peripheral speed and thus shear force. The construction of the stirrer is made in such a way that the bearing between the rotor and the stator creates a shear gap in which high turbulence occurs. The fluid is sucked axially into the dispersing device and expelled through the gap between the rotor and the stator. The flowing liquid is exposed to high pressure, shear and friction, thanks to which the particles are evenly distributed. [9]

\section{RESULTS AND DISCUSSION}

The coating material IP01 was tested using a pull-off test for adhesion (EN ISO 4624) and a cross-cut test (EN ISO 2409). Coating systems IP02, IP03, IP04 were tested to verify their properties and applicability using the following tests: Cross-cut test (EN ISO 2409), Pull-off test for adhesion (EN ISO 4624), Shade change test by CIE Lab (EN ISO 11664-4), Bend test (conical mandrel) (EN ISO 6860), Cupping test (EN ISO 1520), Paints and varnishes - Methods of exposure to laboratory light sources - Part 3: Fluorescent UV lamps (EN ISO 16474-3), Corrosion resistance test (EN ISO 9227), Cyclic thermal loading tests.

\subsection{Mechanical properties}

The measured values of the pull-off test and the evaluation of the fracture type showed that the pull-off of the body was in most cases in the paint or on the border of the substrate and the paint. At IP01 we can observe slightly higher values of adhesion tension. From the average values, it is clear that the coating system IP02 is unsatisfactory in terms of adhesion. This may be due to the interaction of the yellow and thermochromic pigments with the primer. The IP03 coating system has better results in the 2nd series (dispersed by the rotorstator method) (Table 1). The results of the IP04 system in the 2 nd series are affected by the insufficient layer thickness, therefore it is desirable to observe a minimum dry film thickness of $150 \mu \mathrm{m}$. 
Table 1 Test results

\begin{tabular}{|c|c|c|c|c|c|}
\hline & $\begin{array}{c}\text { Marking } \\
\text { P - pre-treated } \\
\text { NP - no pre-treated }\end{array}$ & $\begin{array}{c}\text { Median of } \\
\text { Adhesion } \\
\text { tension (MPa) }\end{array}$ & $\begin{array}{l}\text { Cross- cut test } \\
\text { classification }\end{array}$ & Bend test & Cupping test \\
\hline \multirow{6}{*}{0 . Series } & IP01 (Yellow) P & 7.15 & 1 & \multirow[t]{2}{*}{-} & \multirow[t]{2}{*}{-} \\
\hline & IP01 (Yellow) NP & 7.1 & 1 & & \\
\hline & IP01 (Blue) P & 3.48 & 1 & \multirow[t]{2}{*}{-} & \multirow[t]{2}{*}{-} \\
\hline & IP01 (Blue) NP & 3.65 & 2 & & \\
\hline & IP01 (Black) P & 5.6 & 2 & \multirow[t]{2}{*}{-} & \multirow[t]{2}{*}{-} \\
\hline & IP01 (Black) NP & 3.35 & 2 & & \\
\hline \multirow{6}{*}{ 1. Series } & IP02 P & 0.83 & 4 & \multirow{2}{*}{$\begin{array}{l}\text { Serious } \\
\text { damage }\end{array}$} & \multirow[t]{2}{*}{ Cracks/ flaking } \\
\hline & IP02 NP & 0.17 & 4 & & \\
\hline & IP03 P & 3.26 & 1 & \multirow[t]{2}{*}{ No damage } & \multirow[t]{2}{*}{ No damage } \\
\hline & IP03 NP & 3.49 & 1 & & \\
\hline & IP04 P & 10.06 & 1 & \multirow{2}{*}{$\begin{array}{c}\text { Long } \\
\text { cracks/ } \\
\text { local flaking }\end{array}$} & \multirow[t]{2}{*}{ Cracks/ flaking } \\
\hline & IP04 NP & 8.19 & 1 & & \\
\hline \multirow{2}{*}{ 2. Series } & IP03 P & 7.13 & 1 & \multirow[t]{2}{*}{ No damage } & \multirow[t]{2}{*}{ No damage } \\
\hline & IP04 P & 2.58 & 1 & & \\
\hline
\end{tabular}

The results of the cross-cut test correlate with the measured values of the pull-off test. Significant damage occurs in the IP02 system, so the classification corresponds to level 4. The IP03 and IP04 coating systems in both series show little damage in this section, the classification corresponding to level 1 (Table 1). [12,13,14]

\subsection{Cyclic thermal loading}

This testing was performed in a ThermoScientific Haratherm OMH 400 drying oven, the samples were loaded at $65^{\circ} \mathrm{C}$ for 5 minutes and then cooled by a stream of air from the nozzle for 10 minutes. Thus, 100 cycles were performed and colorfastness was observed. This was measured with a BYK Gardner spectrophotometer. It was recorded by the decrease of the orange hue in the overall system. $[13,14]$

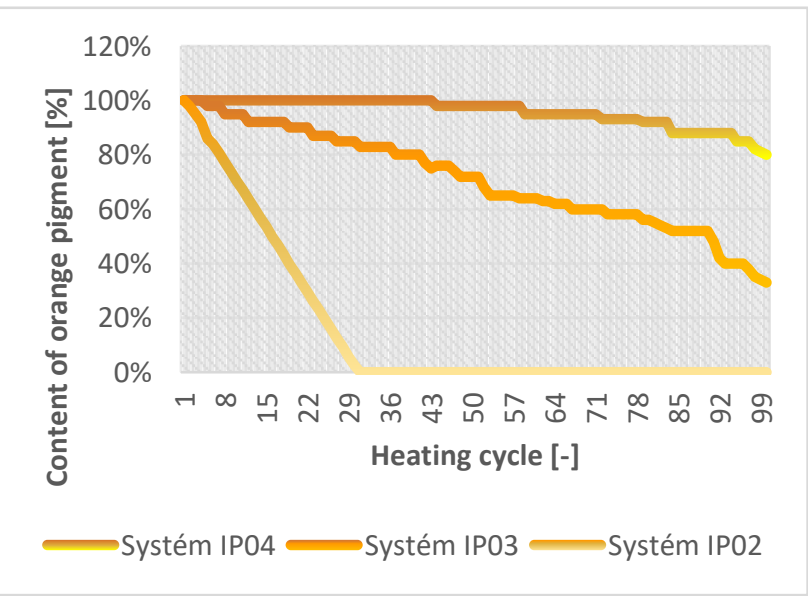

Figure 6 Content of orange hue in paint 1. series

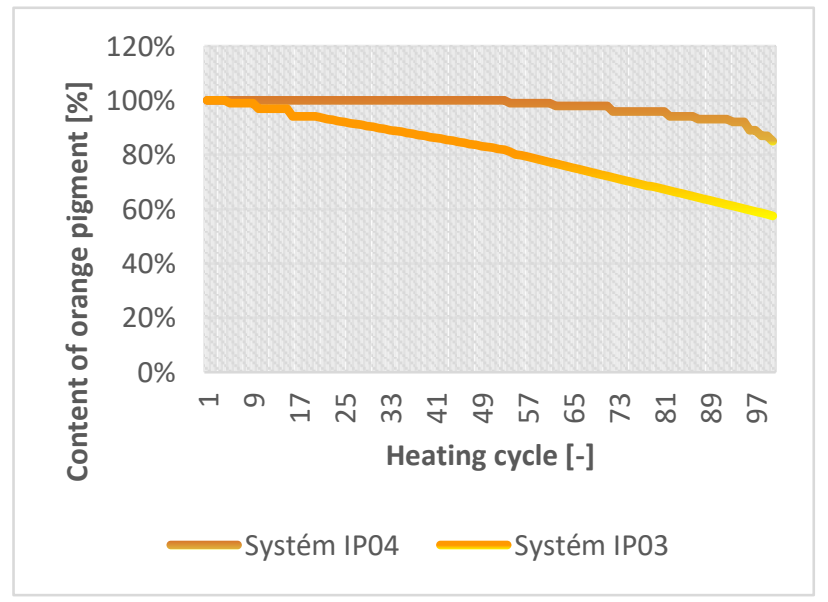

Figure 7 Content of orange hue in paint 2. series 


\section{1st series}

From the graph from 1st series, it is obvious that the coating system IP02 shows rapid degradation of hue. Already in the 18th cycle there is almost no reversible color change. Around the 30th cycle, complete degradation of the thermosensitive pigment was observed. Degradation can also be observed with the IP03 coating system, up to the 80th cycle it has a relatively small deviation from the standard. The best results were obtained with the coating material IP04, where the loss of orange pigment was minimal. However, due to the polyurethane base, the transition temperature increased slightly to values around $60^{\circ} \mathrm{C}$ (Figure 6).

\section{2nd series}

In this series, where the pigment was dispersed by the rotor-stator method, this method proves to be more advantageous because it damages the thermochromic pigment less. Both coating systems (IP03 and IP04) show only a slight decrease in the shade of orange. The change in sample hue in the IP03 system began to manifest itself around 50 cycles, but the loss was minimal. The decrease was even slower for IP04. We can therefore say that the pigment is stable until about the 90th cycle (Figure 7).

\subsection{UV resistance}

UV resistance tests were performed by measuring the hue deviation. The samples were placed in a QUV chamber for one month, and the readings were taken in the first week and then on the last day of the month. This accelerated test simulated two years of direct exposure to sunlight. In the IP02 system, after the first week, there was a significant deviation from the standard, after a month, the thermosensitive pigment completely degraded, and also the degradation of the basic yellow pigment began to show. In the IP03 system, the shade changed after the first week, but the degradation did not continue significantly in the longer period of time. In the IP04 system, the shade also changed after the first week, and in the longer term, the degradation slowly progressed.

For control, the test was performed in natural conditions in the first series for five months, in the second series for three months. Noticeable changes in hue were observed after the first week. Degradation comparable to the previous measurement manifested itself after approximately two months of exposure. Thus, it has been verified that the thermochromic pigment is very sensitive to UV radiation and is suitable for use where it will not be exposed to high radiation exposure. Another possibility is to provide a thermochromic coating with a top UV coating. However, this may change the behaviour of the paint, eg the transition temperature. $[12,13,14]$

\subsection{Corrosion resistance}

\section{1st series}

For the IP02 system, cracking and opacity of the coating occurred after 24 hours, after 168 hours the coating system showed cracking evaluable with a degree of density 5 . The surface layer showed a considerable degree of degradation and is therefore unsuitable for highly corrosive environments. In the IP03 system, slight blistering was observed after 24 hours, after 168 hours the condition remained almost unchanged. We therefore evaluate this system as suitable. No changes were observed for the IP04 system. This coating system is highly resistant to corrosion.

\section{2nd series}

In the IP03 system, significant under corrosion and cracking of the coating was observed after 24 hours, after 168 hours the coating was rusted, evaluable by the degree of Ri 5 . This degradation was probably caused by insufficient coating thickness. The IP04 system showed no visible signs of degradation even after 168 hours. We therefore state high corrosion resistance. $[12,13,14]$ 


\section{CONCLUSION}

In this work, new thermochromic paint was introduced. A multistage formulation was implemented, various coating systems were created and subsequently tested. The IP02 coating system used the same primer as IP01, except that IP02 was further pigmented with the base yellow pigment. This formulation was chosen primarily to verify the properties. IP02 showed insufficient mechanical properties. In contrast, the IP03 and IP04 systems showed satisfactory mechanical properties. Two different dispersion methods have been tested, with the rotor-stator method appearing to be more suitable. Experiments have shown satisfactory technological properties for both systems. However, it is necessary to maintain a sufficient coating thickness. In terms of colour change (number of color transitions), the IP03 and IP04 systems are satisfactory - the number of realized color transitions with a minimum content of orange shade greater than $50 \%$ is 80 cycles for IP03 and 90 cycles for IP04. Paint formulations IP03 and IP04 have been registered as functional sample.

\section{ACKNOWLEDGEMENTS}

\section{The research was supported by project TA ČR CVPÚ (Research center for surface treatments) TE02000011 and SGS19/163/OHK2/3T/12 Research, optimization and innovation of production processes.}

\section{REFERENCES}

[1] DAY, J. H. Thermochromism. In: Chemical Reviews. 1963, s. 65-80.

[2] SEEBOTH, A., LÖTZSCH D. Thermochromic and thermotropic materials. Singapore: Pan Stanford, 2014.

[3] VIK, M. PERIYASAMY A. P. Chromic materials: fundaments, measurements, and applications. Canada: Apple Academic Press, 2018.

[4] BAMFIELD, P., HUTCHINS M. G. Chromic phenomena: technological applications of colour chemistry. 2nd. Cambridge: Royal Soc. of Chemistry, 2010.

[5] BOZP v čislech a grafech. BOZP Statistiky [online]. Praha, 2021 [cit. 2021-5-11]. Available from: http://statistikybozp.vubp.cz/.

[6] PRODUCT INFORMATION LIST: Apex Pigments. Littleport, 2014.

[7] KÖNIGOVÁ, Radana. Komplexní léčba popálenin. Praha: Grada, 1999.

[8] STRĘK, Fryderyk. Míchání a míchací zařizení. Praha: SNTL, 1977.

[9] PAUL, E. L., ATIEMO-OBENG, V. A. and KRESTA, S. M. Handbook of industrial mixing: science and practice. John Wiley \& Sons, Inc., Hoboken, NJ, USA. 2004.

[10] FICKOVÁ, Z.; KUDLÁČEK, J.; DRAŠNAR, P.; MATAS, F.; BENEŠOVÁ, D. Thermochromic Painting Systems. In: Proceedings of International Conference on Innovative Technologies IN-TECH 2014. Rijeka: Faculty of Engineering University of Rijeka, 2014. pp. 313-316.

[11] TATÍČKOVÁ, Z.; KUDLÁČEK, J.; HELLER, J.; MATAS, F.; PEPELNJAK, T. Interactive painting systems. In: INTECH 2015 - International Conference on Innovative Technologies. Rijeka: Faculty of Engineering University of Rijeka, 2015. pp. 447-450.

[12] TATÍČKOVÁ, Z.; KUDLÁČEK, J.; HELLER, J. Interactive Thermosensitive Painting Systems for Safety Purposes. In: IN-TECH 2018 International Conference on Innovative Technologies, Zagreb, Proceedings. Rijeka: Faculty of Engineering University of Rijeka, 2018. p. 227-230.

[13] DRBOUT, V.; HÁKOVÁ, M.; KUDLÁČEK, J.; TATíČKOVÁ, Z.; KREIBICH, V. Nová termochromická nátěrová hmota s akrylátovým základem. [Functional Sample]. 2019.

[14] DRBOUT, V.; HÁKOVÁ, M.; KUDLÁČEK, J.; TATíČKOVÁ, Z.; KREIBICH, V. Nová termochromická nátěrová hmota s polyuretanovým základem. [Functional Sample]. 2019. 